\title{
A Study of the Microbiology of Breast Abscess in a Teaching Hospital in Kuwait
}

\author{
Khalifa Al Benwan ${ }^{a} \quad$ Ahmed Al Mulla ${ }^{b}$ Vincent O. Rotimic \\ Departments of a Microbiology and ${ }^{b}$ Surgery, Al-Amiri Hospital, and ${ }^{\mathrm{C}}$ Department of Microbiology, Faculty of \\ Medicine, Kuwait University, Jabriya, Kuwait
}

\section{Key Words}

Abscess · Antibiotic susceptibility $\cdot$ Breast $\cdot$ Etiology

\begin{abstract}
Objectives: To determine the microbiological profile of breast abscess and assess the antibiotic susceptibility of the causative agents. Materials and Methods: Data obtained from cases of breast abscess over a period of 3.5 years, June 2006 to December 2009, were retrospectively analyzed. Specimens were cultured using optimal aerobic and anaerobic microbiological techniques. The antibiotic susceptibility test was carried out using the methods recommended by the Clinical and Laboratory Standards Institute. One specimen per patient was analyzed. Results: Of the 114 patients, 107 (93.8\%) non-lactating and 7 (6.1\%) lactating women were diagnosed with breast abscess during this period. Of the 114 specimens, 83 (73\%) yielded bacterial growth. Of these, 115 pathogens were isolated with an average of 1.4 pathogens per abscess. Eighteen (22\%) of the 83 specimens yielded mixed bacterial growth. There were more Gram-positive pathogens $(60,52 \%)$ than anaerobes $(32,28 \%)$ and Gram-negative pathogens (22, 19\%). The predominant organisms were methicillin-susceptible Staphylococcus aureus (37, 32\%), methicillin-resistant S. aureus (MRSA; 11, 10\%), Bacteroides spp. $(16,14 \%)$, anaerobic streptococci $(14,12 \%)$ and Pseudomonas aeruginosa (9, 8\%). Of the $48 \mathrm{~S}$. aureus, MRSA
\end{abstract}

accounted for 11 (23\%). All MRSA isolates were susceptible to trimethoprim-sulfamethoxazole and vancomycin. Conclusion: S. aureus was the most common pathogenic organism isolated in breast abscesses at Al-Amiri Hospital, Kuwait, of which $23 \%$ were MRSA. Nearly a third of the cases were caused by anaerobes, particularly $B$. fragilis. The data present a basis for the formation of empirical antimicrobial therapeutic policy in the management of breast abscess.

Copyright $\odot 2011$ S. Karger AG, Basel

\section{Introduction}

Acute bacterial mastitis either resolves under antibiotic therapy or evolves toward a pyogenic abscess. The gold standard for the treatment of breast abscesses is surgical incision, drainage and administration of systemic antibiotics $[1,2]$. This strategy often leaves unpleasant scars and requires regular postoperative changes of dressing. However, recent studies have suggested that sonographically guided aspiration of breast abscesses plus systemic antibiotic drug therapy may be less invasive, with improved cosmetic outcome and a higher cure rate [3-5]. To increase the success rate of acute bacterial mastitis and minimally invasive drainage techniques with adjunctive antimicrobial drug therapy, knowledge about the type of pathogens responsible for breast abscesses and their re-

\section{KARGER \\ Fax +4161306 1234 \\ E-Mail karger@karger.ch}

www.karger.com
C) 2011 S. Karger AG, Basel

1011-7571/11/0205-0422\$38.00/0

Accessible online at:

www.karger.com/mpp
Dr. Khalifa Al Benwan

Department of Microbiology, Al-Amiri Hospital

PO Box 4077

Safat 13041 (Kuwait)

Tel. +965 6691 0508, E-Mail drbanwan@gmail.com 
sistance patterns may help the surgeon to choose the correct empirical treatment. The bacteriology of breast abscesses has been studied in the past, identifying Staphylococcus aureus as the predominant bacterial isolate $[6,7]$.

This study was undertaken to analyze the bacteriology of breast abscesses and to assess the in vitro antimicrobial susceptibility of the causative pathogens in Al-Amiri Hospital, a 400-bed hospital situated in Kuwait City.

\section{Materials and Methods}

Laboratory and hospital records of all female patients who underwent treatment for a breast abscess at Amiri Hospital from June 2006 to December 2009 were carefully reviewed for suspected causative microbial pathogens and an antimicrobial susceptibility pattern. All pus specimens obtained in the operating room were transported immediately in tightly screw-capped sterile universal bottles to the Microbiology Laboratory of Al-Amiri Hospital. All specimens were examined by Gram-stained smears, and processed for isolation of bacteria by inoculating specimens onto a set of selective and non-selective media, namely: blood agar (Oxoid, Basingstoke, UK), MacConkey agar (Oxoid), chocolate agar plates, fastidious anaerobe agar (Oxoid) supplemented with 5\% (v/v) sheep blood and blood agar supplemented with vitamin $\mathrm{K}_{1}(1 \mu \mathrm{g} /$ $\mathrm{ml})$, hemin $(5 \mu \mathrm{g} / \mathrm{ml})$ and gentamicin $(75 \mu \mathrm{g} / \mathrm{ml})$. One inoculated blood agar and MacConkey agar specimen were incubated in air at $37^{\circ} \mathrm{C}$ for $24 \mathrm{~h}$, which was extended to $48 \mathrm{~h}$ if there was no growth. The chocolate agar was incubated in air plus $\mathrm{CO}_{2} 10 \%$ for $24 \mathrm{~h}$; inoculated fastidious anaerobic agar and gentamicin plates were incubated anaerobic jars under atmospheric conditions in the presence of $\mathrm{CO}_{2} 10 \%$ and $\mathrm{H}_{2} 90 \%$ for $48 \mathrm{~h}$, which was extended to a total of 5 days if there was no growth after 48 h. Isolated organisms were identified by conventional microbiological methods, Analytical Profile Index API 20E (bioMérieux, Marcy l'Etoile, France) for Gram-negative aerobes, API Staph (bioMérieux) for staphylococci, API 20 Strep (bioMérieux) for streptococci and enterococci, API 20A (bioMérieux) and gas-liquid chromotography (Chrompak, CP9001, The Netherlands) for the anaerobes.

The antimicrobial susceptibility testing of the bacterial isolates was determined by VITEK 2 susceptibility cards (bioMérieux), and the results were interpreted according to the guidelines of the Clinical and Laboratory Standards Institute (CLSI) [8]. Briefly, inocula were prepared from isolated colonies suspended in sterile distilled water to the $0.5 \mathrm{McF}$ arland turbidity standard. S. aureus was tested for methicillin resistance by using a 1- $\mu$ g oxacillin disc. Gram-negative bacilli were tested for extended-spectrum $\beta$-lactamase (ESBL) production by the doubledisc diffusion test and confirmed by the Etest ESBL method (AB Biodisk, Solna, Sweden) as recommended by the CLSI [8]. The double-disc diffusion test was performed by a standard disk diffusion assay on Müller-Hinton agar (Becton Dickinson). Reference strains of E. coli (ATCC 25922) and Pseudomonas aeruginosa (ATCC 27853) were used as controls for Gram-negative bacteria and were included in all daily runs. S. aureus (ATCC 25923) and E. faecalis (ATCC 929212) were used as Gram-positive control strains.

Etiological Agents of Breast Abscess and Their Antimicrobial Susceptibility Pattern
Table 1. Proportion and frequency of isolation of the etiological agents of breast abscess

\begin{tabular}{llll}
\hline & $\begin{array}{l}\text { Total } \\
(\mathrm{n}=115)\end{array}$ & $\begin{array}{l}\text { Propor- } \\
\text { tion }\end{array}$ & $\begin{array}{l}\text { Fre- } \\
\text { quency }\end{array}$ \\
\hline Gram-positive bacteria & 60 & 52 & 72 \\
$\quad$ Staphylococcus aureus & 37 & 32 & 45 \\
Methicillin-resistant S. aureus & 11 & 10 & 13 \\
Staphylococcus epidermidis & 3 & 3 & 4 \\
Group B streptococci & 1 & 1 & 1 \\
Enterococcus spp. & 4 & 3 & 5 \\
Streptococcus spp. & 4 & 3 & 5 \\
Subtotal & 60 & 52 & 72 \\
\hline
\end{tabular}

\begin{tabular}{lrrr}
\hline Gram-negative bacteria & & & \\
$\quad$ Escherichia coli & 4 & 3 & 5 \\
Klebsiella pneumoniae & 3 & 3 & 4 \\
Proteus mirabilis & 3 & 3 & 4 \\
Pseudomonas aeruginosa & 9 & 8 & 11 \\
Salmonella group G & 1 & 1 & 1 \\
Morgenella morganii & 1 & 1 & 1 \\
Citrobacter diversus & 1 & 1 & 1 \\
\cline { 2 - 4 } Subtotal & 22 & 19 & 26
\end{tabular}

Anaerobes

$\begin{array}{llll}\text { Bacteriodes spp. } & 16 & 14 & 19\end{array}$

$\begin{array}{llll}\text { Anaerobic streptococci } & 14 & 12 & 17\end{array}$

Fusobacterium spp.

\begin{tabular}{lrrr}
\cline { 2 - 4 } Subtotal & 32 & 28 & 39 \\
\hline Candida albicans & 1 & 1 & 1 \\
\hline Total & 115 & 100 & 137 \\
\hline
\end{tabular}

Proportion $=\%$ of isolates to the total number; frequency $=$ $\%$ of the organisms to the number of culture-positive patients $(\mathrm{n}=83)$.

\section{Results}

Of the 114 patients with breast abscesses analyzed in this study, 107 (93.8\%) were lactating women and 7 (6.1\%) were non-lactating. The mean age of the patients was 41 \pm years (range 21-67). A total of 115 pathogens were isolated from pus specimens obtained from 83 of the 114 patients who were diagnosed with BAs, with an average of 1.4 organisms per abscess. Bacterial yield was seen in 83 of the $114(72.8 \%)$ specimens. Of the 83 cultures, 18 (22\%) were positive for multiple organisms and 65 (78\%) were positive for a single organism.

\section{Etiological Isolates}

The overall species distribution is shown in table 1 . $S$. aureus was the predominant pathogen, accounting for 
Table 2. Antimicrobial susceptibility patterns of Gram-positive cocci from breast abscess

\begin{tabular}{lllll}
\hline Antimicrobial agents & $\begin{array}{l}\text { MSSA } \\
(\mathrm{n}=37)\end{array}$ & $\begin{array}{l}\text { MRSA } \\
(\mathrm{n}=11)\end{array}$ & $\begin{array}{l}\text { Enterococcus spp. } \\
(\mathrm{n}=4)\end{array}$ & $\begin{array}{l}\text { Streptococcus spp. } \\
(\mathrm{n}=4)\end{array}$ \\
\hline Ampicillin & - & - & $3(75)$ & $4(100)$ \\
Cephalexin & $37(100)$ & $0(0)$ & - & - \\
Clindamycin & $35(95)$ & $8(73)$ & - & $1(25)$ \\
Cloxacillin & $37(100)$ & $0(0)$ & - & - \\
Co-amoxiclav & $36(97)$ & - & - & $3(75)$ \\
Erythromycin & $34(92)$ & $8(73)$ & $0(0)$ & - \\
Fusidic acid & $35(95)$ & $8(73)$ & - & - \\
Gentamicin & $37(100)$ & $4(36)$ & - & - \\
Penicillin & $4(11)$ & $0(0)$ & $3(75)$ & - \\
Rifampicin & $37(100)$ & $11(100)$ & - & $3(75)$ \\
SMX & $35(95)$ & $11(100)$ & - & $4(100)$ \\
Tetracycline & $34(92)$ & $7(64)$ & - & $4(100)$ \\
Vancomycin & $37(100)$ & $11(100)$ & $4(100)$ \\
\hline
\end{tabular}

Data presented as n (\%). MSSA = Methicillin-susceptible S. aureus; MRSA = methicillin-resistant S. aureus.

$48(42 \%)$ of the causative agents, followed by Bacteroides spp. $(16,14 \%)$, anaerobic streptococci $(14,12 \%)$ and $P$. aeruginosa $(9,8 \%)$. Forty-seven $(47,57 \%)$ of the culture-positive patients were infected with aerobes only. Infections with anaerobes alone were observed in 18 (15\%) cases.

Facultative Gram-positive bacteria were the most commonly isolated pathogens, accounting for 56 (49\%) of all isolates. S. aureus, the predominant Gram-positive bacteria, represented $86 \%$ of all Gram-positive bacteria.

Anaerobic isolates were the second most commonly isolated pathogens, accounting for 32 (28\%) of all isolates. Bacteroides, the predominant anaerobic isolates, comprised $50 \%$ of all anaerobes and $14 \%$ of the total isolates recovered. Anaerobic streptococci were the second most prevalent anaerobic isolates, comprising $44 \%$ of all anaerobes and $12 \%$ of the total isolates recovered.

Aerobic Gram-negative bacteria comprised 22 (19\%) of all isolates. P. aeruginosa, the predominant Gram-negative bacteria, accounted for $37 \%$ of all Gram-negative bacteria and $8 \%$ of the total isolates recovered.

\section{Antimicrobial Susceptibility Pattern}

The antimicrobial susceptibility pattern of the Grampositive cocci is shown in table 2. S. aureus isolates were susceptible to the major drugs used in the management of breast abscesses; 11 and 5\% of S. aureus isolates were resistant to clindamycin and trimethoprim-sulfamethoxazole (SXT), respectively. Of the $48 \mathrm{~S}$. aureus isolates, 15 (31\%) were resistant to methicillin (MRSA). All isolates of MRSA were susceptible to SXT, rifampicin and vancomy- cin, but $4(27 \%)$ isolates were resistant to clindamycin, erythromycin and fusidic acid. The Enterococcus spp. were fully susceptible to vancomycin, while $25 \%$ of the isolates were resistant to ampicillin and penicillin, respectively. The antibiotic resistance pattern of anaerobes is shown in table 3. Metronidazole, amoxicillin-clavulanic acid and piperacillin-tazobactam had excellent activities against all the anaerobes; none of the anaerobes was resistant to these antibiotics. However, $37 \%$ of strains of $B$. fragilis were resistant to clindamycin. The antibiotic resistance pattern of the Gram-negative bacilli is shown in table 4. All Gram-negative bacteria were susceptible to imipenem and amikacin. Ciprofloxacin and piperacillintazobactam had excellent activities against $P$. aeruginosa, K. pneumoniae and Proteus mirabilis. None of the E. coli and $K$. pneumoniae were ESBL producers.

\section{Discussion}

This is the first study to evaluate the susceptibility patterns of bacterial isolates from breast abscesses in Kuwait. Our data indicated that $S$. aureus was the most common cause of breast abscesses in patients presenting to Emergency Department of Al-Amiri Hospital, Kuwait. The predominance of $S$. aureus is similar to the findings that have been reported by other investigators $[7,9]$. In our study, $23 \%$ of all S. aureus isolates were MRSA. This high prevalence of MRSA corresponds to the high prevalence reported for other skin and soft tissue infections in other 
Table 3. Antimicrobial susceptibility patterns of Gram-negative bacilli from breast abscesses

\begin{tabular}{lllll}
\hline Antimicrobial agents & $\begin{array}{l}\text { P. aeruginosa } \\
(\mathrm{n}=9)\end{array}$ & $\begin{array}{l}\text { Proteus spp. } \\
(\mathrm{n}=3)\end{array}$ & $\begin{array}{l}\text { K. pneumoniae } \\
(\mathrm{n}=3)\end{array}$ & $\begin{array}{l}\text { E. coli } \\
(\mathrm{n}=4)\end{array}$ \\
\hline Amikacin & $9(100)$ & $3(100)$ & $3(100)$ & $4(100)$ \\
Amoxicillin clavulanic acid & - & $2(67)$ & $3(100)$ & $3(75)$ \\
Ampicillin & - & $1(33)$ & $0(0)$ & $2(50)$ \\
Cefotaxime & - & $3(100)$ & $3(100)$ & $4(100)$ \\
Ceftazidime & $8(89)$ & - & - & - \\
Cefuroxime & - & $3(100)$ & $3(100)$ & $4(100)$ \\
Ciprofloxacin & $9(100)$ & $3(100)$ & $3(100)$ & $4(75)$ \\
Gentamicin & $9(100)$ & $3(100)$ & $3(100)$ & $3(75)$ \\
Imipenem & $9(100)$ & $3(100)$ & $3(100)$ & $4(100)$ \\
Piperacillin & $8(89)$ & $3(100)$ & $1(33)$ & $2(50)$ \\
Piperacillin-tazobactam & $9(100)$ & $3(100)$ & $3(100)$ & $2(50)$ \\
SMX & - & $1(33)$ & - & $2(50)$ \\
\end{tabular}

Data presented as n (\%).

countries [10-12]. Most of the S. aureus were susceptible to oral drugs commonly used in the treatment of breast abscess such as clindamycin, cephalexin and SXT. Antimicrobial susceptibility patterns of the MRSA isolates in this study are typical of community-associated MRSA from other recent reports [13, 14]. All MRSA isolates demonstrated uniform resistance to oxacillin, signifying a lack of susceptibility to all $\beta$-lactam antibiotics, including cephalosporins. However, a large proportion of the isolates were susceptible to a number of the non- $\beta$-lactam antibiotics, including SXT, rifampicin and vancomycin. A large number of the MRSA isolates in this study were fully susceptible to clindamycin, erythromycin and fusidic acid.

Our findings on the anaerobic component of breast abscess cases are inconsistent with previously reported studies $[6,15]$, which appear to suggest that Bacteroides organisms as a group are a rare cause of breast abscess. Data presented in our study indicate that Bacteroides spp. and anaerobic streptococci constitute the second most common isolates associated with breast abscesses, being present in 14 and $12 \%$ of the patients, respectively. The results of our study also indicate a higher prevalence rate of anaerobes than that of $5 \%$ reported in a study on breast abscesses in the USA [9]. Amoxicillin-clavulanic acid, metronidazole, piperacillin-tazobactam and clindamycin were the most active antimicrobial agents against these anaerobes. P. aeruginosa was the most common Gram-negative aerobic bacteria recovered from our patients. This finding accords with data obtained by Moazzez et al. [9]. The Enterobacteriaceae isolates were non-
Table 4. Antimicrobial susceptibility patterns of anaerobic bacterial isolates from breast abscess infections

\begin{tabular}{lccl}
\hline Antimicrobial agents & $\begin{array}{l}\text { Anaerobic } \\
\text { streptococci } \\
(\mathrm{n}=14)\end{array}$ & $\begin{array}{l}\text { Bacteroides } \\
\text { species } \\
(\mathrm{n}=16)\end{array}$ & $\begin{array}{l}\text { Fusobacterium } \\
\text { species } \\
(\mathrm{n}=2)\end{array}$ \\
\hline Amoxicillin & - & - & - \\
Ampicillin/CA & $14(100)$ & $16(100)$ & $2(100)$ \\
Erythromycin & $14(100)$ & - & - \\
Cefoxitin & $14(100)$ & $16(100$ & - \\
Clindamycin & $14(100)$ & $10(63)$ & - \\
Metronidazole & $14(100)$ & $16(100)$ & $2(100)$ \\
Penicillin-G & $14(100)$ & $0(0)$ & - \\
Piperacillin & $14(100)$ & $16(100)$ & - \\
Piperacillin/tazobactam & $14(100)$ & $16(100)$ & $2(100)$ \\
Tetracycline & - & - & - \\
Vancomycin & - & - & - \\
\hline
\end{tabular}

ESBL producers making the choice of many oral drugs, such as the fluoroquinolones and amoxicillin-clavulanic acid, feasible in patients with breast abscesses due to these organisms. In severe cases needing hospitalization and perhaps parenteral antimicrobial therapy, such drugs as imipenem, amikacin and piperacillin-tazobactam would be useful, as all isolates were susceptible to them. With minimally invasive management of breast abscesses, such as ultrasound-guided drainage plus systemic antibiotic drug therapy, understanding the current bacteriological features of these abscesses is essential to determining the correct choice of empirical antibiotic therapy. Our data 
indicates that $S$. aureus, Bacteroides spp., anaerobic streptococci as well as MRSA were the most common etiological agents of breast abscesses in our hospital. Appropriate antibiotic therapy, which should be effective against aerobes and anaerobes, may have a significant benefit in the initial management of acute breast abscess, as $28 \%$ of all isolates in our study population were anaerobic. In contrast to SXT, which is recommended as first-line therapy by Moazzez et al. [9], the results of our study support the use of clindamycin or amoxicillin-clavulanic acid as the best empirical oral antibiotic drug therapy for patients with breast abscesses.

\section{Conclusion}

Data presented in this study indicate that antibiotics chosen for the treatment of breast abscess should be those effective against both aerobes and anaerobes, but species' distributions and their susceptibility to antibiotics are changing all over the world. It requires regular monitoring in order to make reliable information available for optimal empirical therapy for patients with breast abscesses.

\section{References}

1 Meguid MM, Oler A, Numann PJ, Khan S: Pathogenesis-based treatment of recurring subareolar breast abscesses. Surgery 1955; 118:775-782.

$>2$ Dixon JM: Outpatient treatment of non-lactational breast abscesses. Br J Surg 1992;79: 56-57.

-3 Christensen AF, Al-Suliman N, Nielsen KR, Vejborg I, Severinsen N, Christensen H, Nielsen MB: Ultrasound-guided drainage of breast abscesses: results in 151 patients. $\mathrm{Br} \mathrm{J}$ Radio J 2005;78:186-188.

4 Thirumalaikumar S, Kommu S: Best evidence topic reports: aspiration of breast abscesses. Emerg Med J 2004;21:333-334.

$\checkmark 5$ Leborgne F, Leborgne F: Treatment of breast abscesses with sonographically guided aspiration, irrigation and instillation of antibiotics. AJR Am J Roentgenol 2003;181:10891091.

6 Walker AP, Edmiston CE Jr, Krepel CJ, Condon RE: A prospective study of the microflora of nonpuerperal breast abscess. Arch Surg 1988;123:908-911.
7 Brook L: Microbiology of non-puerperal breast abscesses. J Infect Dis 1988;157:377379.

8 Clinical and Laboratory Standards Institute: Performance Standards for Antimicrobial Disk Tests: Approved Standards, ed 9 (CLSI Document M2-A9, 26 No. 1). Wayne, Clinical and Laboratory Standards Institute, 2006.

$>9$ Moazzez A, Rebecca L, Kelso RL, Towfigh S, Sohn H, Berne TV, Rodney J, Mason RJ: Breast abscess bacteriologic features in the era of community-acquired methicillinresistant Staphylococcus aureus epidemics. Arch Surg 2007;142:881-884.

10 Chambers HF: The changing epidemiology of Staphylococcus aureus? Emerg Infect 2001; 7:178-182.

11 Eady EA, Cove JH: Staphylococcal resistance revisited: community-acquired methicillinresistant Staphylococcus aureus: an emerging problem for the management of skin and soft tissue infections. Curr Opin Infect Dis 2003;16:103-124.
2 Ala'Aldeen D: A non-multiresistant community methicillin-resistant Staphylococcus aureus exposes its genome. Lancet 2002;359: 1791-1792.

13 Adhikari RP, Cook MG, Lamont I, Lang S, Heffernan H, Smith JM: 2002. Phenotypic and molecular characterization of community occurring, Western Samoan phage pattern methicillin-resistant Staphylococcus aureus. J Antimicrob Chemother 2002;50:825831.

14 Almer LS, Shortridge VD, Nilius AM, Beyer JM, Soni NB, Bui MH, Stone GG, Flamm RK: Antimicrobial susceptibility and molecular characterization of community-acquired methicillin-resistant Staphylococcus aureus. Diagn Microbiol Infect Dis 2002;43:225232.

15 Pearson HE: Bacteroides in areolar breast abscesses. Surg Gynecol Obstet 1967;125:800880 . 